\title{
Kinetics of Ion Transport through Supramolecular Channels in Single Crystals**
}

\author{
Cyrille D. Assouma, Aurélien Crochet, Yvens Chérémond, Bernd Giese, and \\ Katharina M. Fromm*
}

Reactions in single crystals of supramolecular assemblies are most often associated with the breaking of the crystals into polycrystalline or amorphous materials, induced by the major transformations and related strain during the reaction. ${ }^{[1]}$ The rare examples in which the single crystallinity is maintained in supramolecular compounds during the reaction are based on the neutral sorption and desorption of guest molecules in robust three-dimensional (3D) metal-organic frameworks $(\mathrm{MOFs})^{[2]}$ or [2+2] photodimerization processes in organic compounds or coordination polymers. ${ }^{[3]}$ Ion-exchange reactions, as reported, for example, for zeolites ${ }^{[4]}$ and polycrystalline $\mathrm{MOFs}^{[2]}$ are often incomplete and determined by methods such as atomic absorption spectroscopy and energy dispersive X-ray spectroscopy. ${ }^{[5]}$ While 3D MOFs have been compared to zeolites, ${ }^{[4]}$ we now show the generation of onedimensional (1D) channel systems based on crown ether ligands which perform alkali cation transport in analogy to ion channels in biology ${ }^{[6 a]}$ and synthetic organic channels in membranes. ${ }^{[6 \mathrm{~b}-\mathrm{e}]}$ Crown ether complexes with alkali metal ions have been described, ${ }^{[7]}$ yet the number of compounds in which this kind of ligand assembles into 1D stacks is extremely limited. ${ }^{[7 a-c, e]}$ In the current study we used trihalide anions of the type $\mathrm{X}_{3}^{-}, \mathrm{X}_{2} \mathrm{Y}^{-}$, and $\mathrm{XY}_{2}^{-}(\mathrm{X}=\mathrm{I}, \mathrm{Y}=\mathrm{Br})$ as structural pillars, which induce the stacking of dibenzo[18]crown-6 molecules (DB[18]C6, Figure 1). Single crystals of the resulting channel systems turned out to allow fast alkali cation exchange. To our knowledge, this is the first time that the activation energy for cation transport could be measured in supramolecular stacks. The crystals are very stable during these experiments as they remain unchanged in form and size.

Compound 1a " $\left[\mathrm{K}_{4}(\mathrm{DB}[18] \mathrm{C} 6)_{8}\left(\mathrm{H}_{2} \mathrm{O}\right)_{8}\left(\mathrm{I}_{3}\right)_{4}\right]_{n}$ " (Figure 1) was obtained as large rodlike single crystals (monoclinic, $P 2^{[8]}$ ) from the reaction of $\mathrm{KI}_{3}$ with $\mathrm{DB}[18] \mathrm{C} 6$. Amazingly, we observe three types of parallel and differently filled channels made up of DB[18]C6 molecules between quasi-linear chains of triiodide anions running along the $b$-axis (Figure 1 ).

Channel type $\mathrm{C} 1$ (Figure 2) is filled with linearly arranged, alternating water molecules and $\mathrm{K}^{+}$ions, the latter being

[*] C. D. Assouma, Dr. A. Crochet, Y. Chérémond, Prof. Dr. B. Giese, Prof. Dr. K. M. Fromm

Department of Chemistry, University of Fribourg

Chemin du Musée 9, 1700 Fribourg (Switzerland) E-mail: katharina.fromm@unifr.ch

[**] We thank the Swiss National Science Foundation, the University of Fribourg, and FriMat for generous support. C.D.A. thanks the Swiss Confederation for a stipend.

Supporting information for this article is available

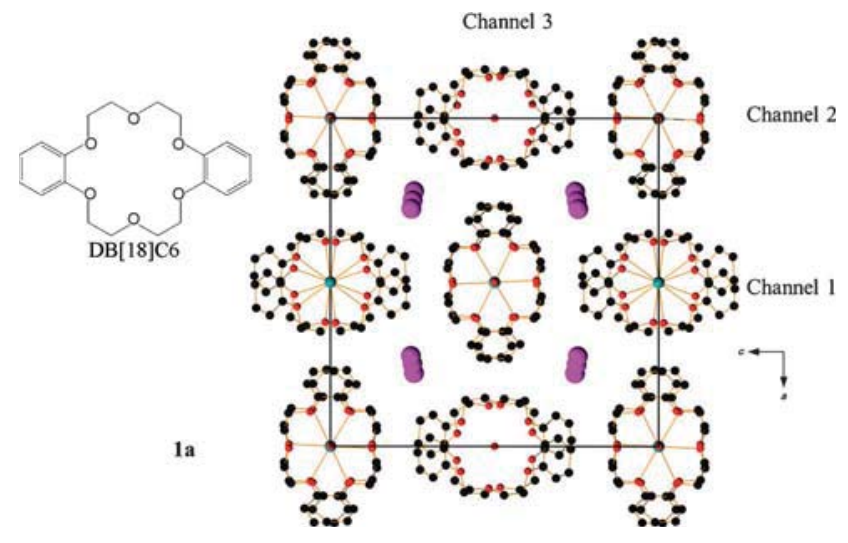

Figure 1. Left: $\mathrm{DB}[18] \mathrm{C} 6$ molecule. Right: unit cell for 1 a along $b$, with two $\mathrm{C} 2$, one $\mathrm{C} 1$, and one $\mathrm{C} 3$ channels per unit cell; $\mathrm{H}$ atoms omitted for clarity; black C, red O, violet I, blue K. Channel 1 runs "up", phenyl rings point towards the reader or to the left, in channel 3 they point "down" or to the right, in channels C2 have one channel points "up", the other "down".

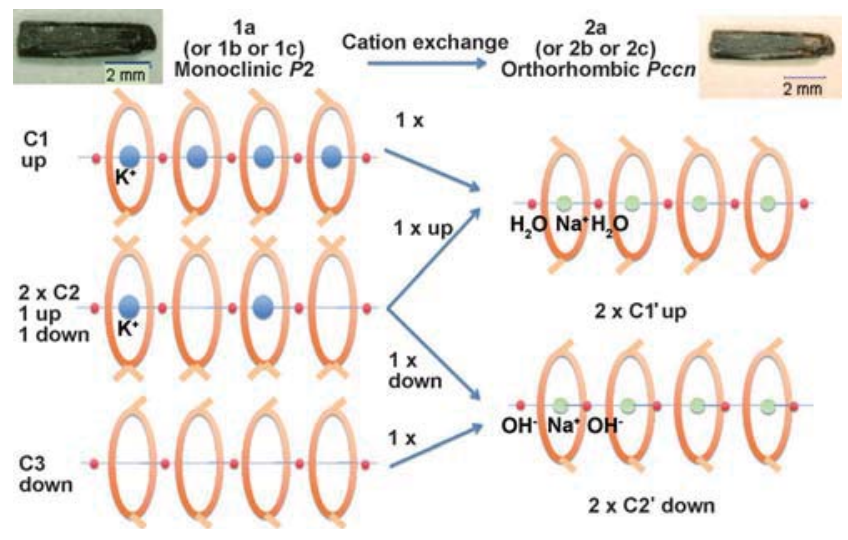

Figure 2. Schematic side view of the three different channels of 1 a (1 b or $1 \mathrm{c}$ ) with indication of the orientation of the phenyl groups (left), and proposed transformation into $\mathbf{2 a}$ ( $\mathbf{2}$ b or $\mathbf{2} \mathbf{c}$ ) (right).

placed in the cavity of the crown ether ligand. In channels of type C2, every second crown ether molecule remains empty, while the first is filled with a $\mathrm{K}^{+}$ion, to which two water molecules are coordinated in axial positions. A third channel type, C3, contains empty DB[18]C6 units with water molecules in between (Figure 2, left). In the unit cell, the orientation of the phenyl groups of the DB[18]C6 ligands is opposite in the two C2-type channels. Antiparallel stacks, running "up" and "down", are also observed for channels C1 and C3. The crown ether molecules of channels C2 are almost 
perfectly stacked with respect to the phenyl groups, while in $\mathrm{C} 1$ and $\mathrm{C} 3$ channels, the aromatic rings are offset by roughly $20^{\circ}$.

Compounds isostructural to $\mathbf{1}$ a which also crystallized in the space group $P 2, \mathbf{1 b}$ and $\mathbf{1 c}$, were also obtained with the heterotrihalide ions $\mathrm{Br}_{2} \mathrm{I}^{-}$and $\mathrm{BrI}_{2}^{-}$, respectively (see the Supporting Information). The trihalide ions are all quasilinear, but tilted by about $12^{\circ}$ relative to the $b$-axis, such that the interaction between the third halide of one anion can form a halogen bond to the first atom of the next trihalide. ${ }^{[9]}$

Based on the stacking of the crown ether moieties and the resulting channels, the structure of $\mathbf{1}$ seems to be predestined for cation transport. Thus, single crystals of $\mathbf{1}$ a (results for $\mathbf{1} \mathbf{b}$ are given in the Supporting Information) were exposed to $\mathrm{NaOH}$ solutions. For example, a single crystal of $\mathbf{1 a}$ with dimensions of $0.37 \mathrm{~cm} \times 0.1 \mathrm{~cm} \times 0.1 \mathrm{~cm}$ was immersed in $1 \mathrm{M}$ $\mathrm{NaOH}$ for $24 \mathrm{~h}$, washed, and-unchanged in appearanceremeasured by single-crystal X-ray diffraction. The space group had changed to orthorhombic $P$ ccn with almost unmodified unit cell parameters. This is possible as the $\beta$ angle in $\mathbf{1 a}$ is very close to the required $90^{\circ}$ for an orthorhombic system, allowing a smooth single-crystal-tosingle-crystal transition. The new compound is found to be $\left[\mathrm{Na}_{2}(\mathrm{DB}[18] \mathrm{C} 6)_{2}\left(\mathrm{H}_{2} \mathrm{O}\right)(\mathrm{OH}) \mathrm{I}_{3}\right](\mathbf{2 a})$ (Figure 2) ${ }^{[10]}$ Two channels with different filling, namely an alternating chain of water molecules and $\mathrm{Na}^{+}$ions in $\mathrm{Cl}^{\prime}$, and an alternating chain of $\mathrm{HO}^{-}$and $\mathrm{Na}^{+}$ions in $\mathrm{C}^{\prime}$, are now found, as corroborated by the following bond lengths: in $\mathrm{C} 2^{\prime}$ : Na1-O7 2.17(2) $\AA$, Na1-O7' 2.51(2) $\AA$; in $\mathrm{C1}^{\prime}$ : in $\mathrm{C}^{\prime}$, Na2-O8 of 2.37(2) $\mathrm{A}, \mathrm{Na} 2-$ O8' 2.31(2) A. The two channel types run antiparallel to each other. It is therefore probable that $\mathrm{C} 1$ and the $\mathrm{C} 2$ channels parallel to $\mathrm{C} 1$ of $\mathbf{1}$ a yield both $\mathrm{C1}^{\prime}$-type channels in $\mathbf{2} \mathbf{a}$, while $\mathrm{C} 3$ and the $\mathrm{C} 2$ channels parallel to $\mathrm{C} 3$ give the $\mathrm{C} 2$ ' channels (Figure 2). ${ }^{[*]}$

Direct attempts to synthesize the $\mathrm{Na}$ analogue of $\mathbf{1 a}$ by replacing $\mathrm{KI}_{3}$ by $\mathrm{NaI}_{3}$ led to $[\mathrm{Na}(\mathrm{DB}[18] \mathrm{C6})$ $\left.\left(\mathrm{H}_{2} \mathrm{O}\right)_{2}(\mathrm{DB}[18] \mathrm{C} 6) \mathrm{I}_{3}\right]$ (3a ; see the Supporting Information). In contrast to $\mathbf{1} \mathbf{a}$ with three different channels and $\mathbf{2} \mathbf{a}$ with two different ones, all channel fillings of $\mathbf{3} \mathbf{a}$ are identical and contain $\mathrm{Na}^{+}$ions in the crown ether cavity and axially bound water molecules. $^{[* *]}$ The $\mathrm{Na}-\mathrm{O}$ distances for $\mathbf{3 a}$ are more symmetric than in $\mathbf{2 a}$, and vary between 2.293(7) and 2.317(7) $\AA$. Yet, there are two channel types that differ only in the relative offset of the phenyl groups of the stacked $\mathrm{DB}$ [18]C6 units. Analogous experiments with $\mathrm{Br}_{2} \mathrm{I}^{-}$and $\mathrm{BrI}_{2}^{-}$ as anions led to the same results (see the Supporting Information).

In all compounds, elongated thermal ellipsoids for the cations and water molecules along the channel direction indicate possible ion and water mobilities. We therefore measured the rates and activation energies for the ion-

[*] Indeed, it is more likely that the offset of the phenyl groups with respect to each other changes, rather than that the orientation of the phenyl groups is inverted during the transformation process.

[***] The $\mathrm{Na}^{+}$ions can only be refined on split positions such that every crown ether ligand contains half of a cation. Attempts to identify a superstructure in which every second crown ether moieties are filled did not succeed. exchange process $\mathbf{1} \mathbf{a}, \mathbf{b} \rightarrow \mathbf{2} \mathbf{a}, \mathbf{b}$. A key assumption is that the free energy of ion exchange for monovalent ions should be negative when a smaller cation enters the channel of high charge density. This was corroborated by experimental data for faujasite, ${ }^{[11]}$ and is confirmed by our above-described exchange of potassium by sodium ions. The rates of ion exchange in membranes and/or microporous materials depend on several parameters: an interdiffusion coefficient for entering and exiting cations takes into account driving forces due to the concentration gradient (Fickian) and polarization (Nernst-Planck), ideality or nonideality of the exchanger, and couplings between ion-ion and ion-water fluxes. ${ }^{[12]}$

Kinetic experiments on the ion-exchange reaction $\mathbf{1} \rightarrow \mathbf{2}$ in our single-crystalline material were carried out using device A (Figure 3). The transport of $\mathrm{Na}^{+}$from compartment a to compartment b was studied at two temperatures, $296 \mathrm{~K}$ and $323 \mathrm{~K}$, over roughly $7 \mathrm{~h}$ by conductivity measurements. In addition the $\mathrm{Na}^{+}$concentrations in compartment $\mathrm{b}$ where determined by inductively coupled plasma optical emission spectrometry (ICP-OES).

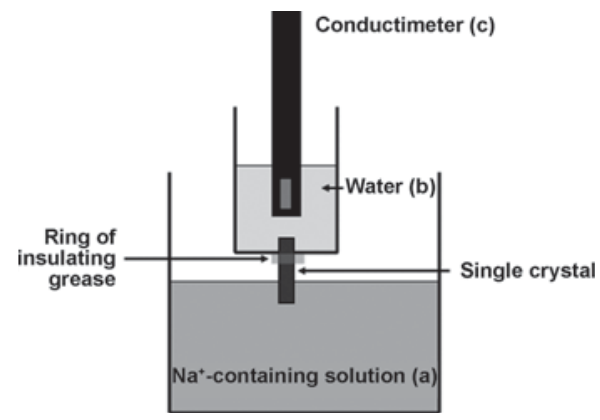

Figure 3. Device A used to measure $\mathrm{Na}^{+}$conductivity.

We analyzed the transport of monovalent ions in $\mathbf{1 a}$ as a pseudo zero-order kinetic because the concentration of sodium ions in compartment a is extremely high, while that in compartment $\mathrm{b}$ increases to only a comparatively low value (Figure 3). The single crystals did not dissolve; their shape and their size persisted during the transport measurements. Determination of the rate constants $k$ at two temperatures $\left(k_{1}\right.$ and $k_{2}$ ) allowed the calculation of the activation energy $E_{\mathrm{a}}$ by the Arrhenius law [Eq. (1)], where $R$ is the gas constant, $E_{\mathrm{a}}$ is the activation energy needed for ion transport, and $A$ is a constant.

$k=A e^{-\frac{E_{1}}{R T}}$ or $\ln k=-\frac{E_{\mathrm{a}}}{R T}+\ln A$

Compounds $\mathbf{1 a}$ and $\mathbf{1 b}$ were both used, and the kinetic studies on the sodium ion transport gave the same results within the experimental error. The time dependence of the sodium ion concentration in compartment b at $296 \mathrm{~K}$ and $323 \mathrm{~K}$, using compound $\mathbf{1 b}$ as an example, is shown in Figure 4 (for 1 a see the Supporting Information). The conductivity increases linearly with the time, which is in agreement with the zero-order kinetic law. The values are corrected versus the 


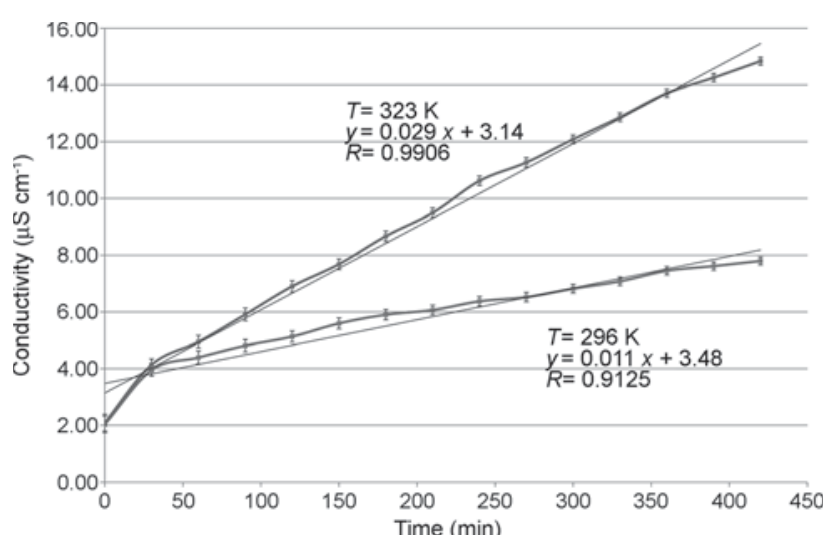

Figure 4. Conductivity measurement with a single crystal $(0.7 \mathrm{~cm} \times 0.1 \mathrm{~cm} \times 0.1 \mathrm{~cm})$ of " $\left[\mathrm{K}_{4}(\mathrm{DB}[18] \mathrm{C} 6)_{8}\left(\mathrm{H}_{2} \mathrm{O}\right)_{8}\left(\mathrm{Br}_{2} \mathrm{I}\right)_{4}\right]_{n}$ " $1 \mathrm{~b}$, showing the time dependence of $\mathrm{Na}^{+}$conductivity at 296 and $323 \mathrm{~K}$; error bars for three measurements.

ionic conductivities obtained by using measurements in which the two reservoirs a and $b$ contain ultrapure water. The conductivity at $323 \mathrm{~K}$ increased as expected more rapidly than that at $296 \mathrm{~K}$. From the slopes (conductivity versus time), rate constants of $(1.8 \pm 0.2) \times 10^{-4} \mathrm{~mol} \mathrm{~L}^{-1} \mathrm{~s}^{-1}$ at $296 \mathrm{~K}$ and $(4.8 \pm$ $0.5) \times 10^{-4} \mathrm{~mol} \mathrm{~L}^{-1} \mathrm{~s}^{-1}$ at $323 \mathrm{~K}$ can be calculated for $\mathbf{1 b}$. This leads to a ratio of $k_{1} / k_{2}$ of $2.6 \pm 0.4$. The ratio of the $\mathrm{Na}^{+}$ concentrations measured in compartment $\mathrm{b}$ after $7 \mathrm{~h}$ at both temperatures (Table 1) confirms this. For compound 1a,

Table 1: Sodium ion concentration $\left(\mathrm{mg} \mathrm{L}^{-1}\right)$ in compartment b after $7 \mathrm{~h}$ of sodium transfer through a single crystal of $\mathbf{1} \mathbf{a}$ and $\mathbf{1} \mathbf{b}$ $(0.7 \mathrm{~cm} \times 0.1 \mathrm{~cm} \times 0.1 \mathrm{~cm})$.

\begin{tabular}{lll}
\hline Compound & $296 \mathrm{~K}$ & $323 \mathrm{~K}$ \\
\hline $1 \mathrm{a}$ & $0.30 \pm 0.04$ & $0.48 \pm 0.05$ \\
$1 \mathrm{~b}$ & $0.22 \pm 0.04$ & $0.58 \pm 0.01$ \\
\hline
\end{tabular}

a value of $2.4 \pm 0.9$ was obtained. The $E_{\mathrm{a}}$ value could therefore be determined to $(27 \pm 4) \mathrm{kJ} \mathrm{mol}^{-1}$. This activation enthalpy value is only slightly higher than that of superionic conductor materials $\left(10-24 \mathrm{~kJ} \mathrm{~mol}^{-1}\right){ }^{[12]}$ This fast sodium ion transport from water through a crystal of $\mathbf{1}$ is in accord with the low complexation constants of $\mathrm{Na}^{+}(\log K=1.16)$ and of $\mathrm{K}^{+}$ $(\log K=1.67)^{[13]}$ for DB[18]C6 monomers in water as solvent. We interpret the ion-exchange reaction $\mathbf{1} \rightarrow \mathbf{2}$ as a gliding/ hopping process of the ions through the channels of the single crystals with a low energy barrier between the individual cation sites inside the channels of the crystal lattice.

Interestingly, $\mathrm{Na}^{+}$transport through the $\mathrm{K}^{+}$-containing crystal of $\mathbf{1}$ is much faster than $\mathrm{K}^{+}$transport through the $\mathrm{Na}^{+}$containing crystal 2. Using $1 \mathrm{M} \mathrm{KOH}$ in compartment a of device A (Figure 3) leads to an ion-transport rate through crystal 2 of only ca. $1 \times 10^{-6} \mathrm{~mol} \mathrm{~L}^{-1} \mathrm{~s}^{-1}$ at $296 \mathrm{~K}$ (see the Supporting Information). This can be explained by the fact that in compound $\mathbf{1}$ three different channel types are present in the unit cell, one of which contains no cations and which can, in the initial step, bind sodium ions on the side where the single crystal is immersed in $\mathrm{NaOH}$. This has to be the case as in the final structure of $\mathbf{2}$ no cation-free channels remain. Following this first binding of sodium ions, excess positive charge has to be eliminated. This is more likely to occur on the other end of the single crystal where ions are hydrated by pure $\mathrm{H}_{2} \mathrm{O}$ rather than at the $\mathrm{NaOH}$-containing side where they would compete with $\mathrm{Na}^{+}$, and hence a directed ion transport through the channels is induced. The $\mathrm{K}^{+}$transport through 2 to give $\mathbf{1}$ is disfavored as all channels contain ions, out of which $25 \%$ would have to become ion free. Thus, the different structures of the $\mathrm{K}^{+}$-containing crystal $\mathbf{1}$ and the $\mathrm{Na}^{+}$containing crystal $\mathbf{2}$ explain the extremely different rates (factor 180 at $296 \mathrm{~K}$ ) for the cation exchange.

The question arises whether lithium ions can also be transported/conducted through single crystals of the compound series 1, 2, and 3. Exposure of any of these single crystals to $\mathrm{LiI}$ or $\mathrm{LiOH}$ solutions either by immersion or by use of device A, however, led to decomposition of the single crystals into a white powder, most of which was identified as LiI and crown ether. This is mostly because the small cation $\mathrm{Li}^{+}$destabilizes the trihalides and hence the pillars, which are apparently needed to maintain the solid-state scaffold structure. If these pillars are destroyed, the crown ether moieties no longer stack and the supramolecular assembly falls apart.

Conclusion: Trihalide ions can be used as structural pillars to assemble three differently filled supramolecular channels based on DB[18]C6. The $\mathrm{K}^{+}$-containing single crystals of type 1 have a robust sublattice of crown ether stacks for $\mathrm{Na}^{+}$ exchange. Kinetic experiments at different temperatures show that these supramolecular crystals are excellent ion conductors.

[1] a) G. J. Halder, C. J. Kepert, Aust. J. Chem. 2006, 59, 597-604; b) S. Takahashi, H. Miura, H. Kasai, S. Okada, H. Oikawa, H. Nakanishi, J. Am. Chem. Soc. 2002, 124, 10944-10945.

[2] For example: a) H. J. Park, D.-W. Lim, W. S. Yang, T.-R. Oh, M. P. Suh, Chem. Eur. J. 2011, 17, 7251-7260; b) M.-S. Chen, M. Chen, S. Takamizawa, T. Okamura, J. Fan, W.-Y. Sun, Chem. Commun. 2011, 47, 3787-3789; c) T. Jacobs, J.-A. Gertenbach, D. Das, L. J. Barbour, Aust. J. Chem. 2010, 63, 573-577; d) S. M. Mobin, A. K. Srivastava, P. Mathur, G. K. Lahiri, Dalton Trans. 2010, 39, 1447-1449; e) S. M. Mobin, A. K. Srivastava, P. Mathur, G. K. Lahiri, Inorg. Chem. 2009, 48, 4652-4654; f) B. Li, R.-J. Wei, J. Tao, R.-B. Huang, L.-S. Zheng, Z. Zheng, J. Am. Chem. Soc. 2010, 132, 1558-1566; g) M.-L. Cao, H.-J. Mo, J.-J. Liang, B.-H. Ye, CrystEngComm 2009, 11, 784-790; h) S. M. Neville, G. J. Halder, K. W. Chapman, M. B. Duriska, P. D. Southon, J. D. Cashion, J.-F. Létard, B. Moubaraki, K. S. Murray, C. J. Kepert, J. Am. Chem. Soc. 2008, 130, 2869-2876; i) C.-D. Wu, W. Lin, Angew. Chem. 2005, 117, 1994-1997; Angew. Chem. Int. Ed. 2005, 44, 1958 -1961; j) J. Zhao, L. Mi, J. Hu, H, Hou, Y. Fan, J. Am. Chem. Soc. 2008, 130, 15222-15223.

[3] a) D. Liu, Z.-G. Ren, H.-X. Li, J.-P. Lang, N.-Y. Li, B. F. Abrahams, Angew. Chem. 2010, 122, 4877-4880; Angew. Chem. Int. Ed. 2010, 49, 4767-4770; b) Q. Chu, D. C. Swenson, L. R. 
MacGillivray, Angew. Chem. 2005, 117, 3635-3638; Angew. Chem. Int. Ed. 2005, 44, 3569-3572; c) J. B. Benedict, P. Coppens, J. Phys. Chem. A 2009, 113, 3116-3120.

[4] For example: G. Ferey in From Zeolites to Porous MOF Materials (Eds: R. Xu, Z. Gao, J. Chen, W. Yan), Elsevier, Amsterdam, 2007, pp. 66-84.

[5] a) W.-G. Lu, L. Jiang, X.-L. Feng, T.-B. Lu, Inorg. Chem. 2009, 48, 6997-6999; b) J. An, N. L. Rosi, J. Am. Chem. Soc. 2010, 132 , 5578-5579; c) G. Calleja, J. A. Botas, M. Sanchez-Sanchez, M. G. Orcajo, Int. J. Hydrogen Energy 2010, 35, 9916-9923; d) S. Liu, J. Li, F. Luo, Inorg. Chem. Commun. 2010, 13, 870-872.

[6] a) "Biological Membrane Ion Channels-Dynamics, Structure and Applications": Biological and Medical Physics, Biomedical Engineering (Eds.: S.-H. Chung, O. S. Anderson, V. V. Krishnamurthy), Springer, Berlin, 2007, DOI: 10.1007/0-387-68919-2; b) J. K. W. Chui, T. M. Fyles, Chem. Soc. Rev. 2012, 41, 148-175; c) S. Matile, A. Vargas Jentzsch, J. Montenegro, A. Fin, Chem. Soc. Rev. 2011, 40, 2453-2474; d) G. W. Gokel, N. Berkey, New J. Chem. 2009, 33, 947-963; e) P.-L. Boudreault, N. Voyer, Org. Biomol. Chem. 2007, 5, 1459-1465.

[7] a) R. D. Bergougnant, K. M. Fromm, Solid State Sci. 2007, 9, 580-587, and references therein; b) K. M. Fromm, E. D. Gueneau, H. Goesmann, C. G. Bochet, Z. Anorg. Allg. Chem. 2003, 629，597-600; c) R. D. Bergougnant, A. Y. Robin, K. M. Fromm, Cryst. Growth Des. 2005, 36, 4548-4550; d) R. D. Bergougnant, A. Y. Robin, K. M. Fromm, Tetrahedron 2007, 63, 10751 - 19757; e) L. Kloo, P. H. Svensson, M. J. Taylor, J. Chem. Soc. Dalton Trans. 2000, 1061-1065.
[8] Under the same conditions Chekhlov obtained a compound described as $\left[\mathrm{K}(\mathrm{DB}[18] \mathrm{C} 6)\left(\mathrm{H}_{2} \mathrm{O}\right)\right] \mathrm{I}_{3}$ with an orthorhombic space group $P$ ccn, which we could not confirm. A. N. Chekhlov, $Z h$. Neorg. Khim. 2009, 54, 516-520. When we solved the structure of $\mathbf{1} \mathbf{a}$, the orthorhombic space group was also proposed, but the monoclinic space group gives the best results. In addition, cautious heating of single crystals of $\mathbf{1 a}$ to $180^{\circ} \mathrm{C}$ for $2 \mathrm{~h}$ yields water-free crystals of $\mathbf{1} \mathbf{a}^{\prime},\left[\{\mathrm{KI}(\mathrm{DB}[18] \mathrm{C} 6)\}_{2}(\mathrm{DB}[18] \mathrm{C} 6)\right]$ (monoclinic, $P 2_{1} / n$, Supporting Information), containing $\mathrm{K}^{+}$-filled DB[18]C6 units as well as empty ones, thus indirectly confirming the initial presence of three channel types in $\mathbf{1 a}$.

[9] P. Metrangolo, G. Resnati, Chem. Eur. J. 2001, 7, 2511-2519.

[10] The origin of the unit cell for $\mathbf{2} \mathbf{a}$ is now on the central halogen atom of the trihalide while it was on a $\mathrm{K}^{+}$ion in $\mathbf{1} \mathbf{a}$.

[11] a) R. P. Townsend in Introduction to Zeolite Science and Practice (Eds.: H. van Bekkum, E. M. Flanigen, J. C. Jansen), Elsevier, Amsterdam, 1991, pp. 359-391; b) R. M. Barrer, R. F. Bartholomew, L. V. C. Rees, J. Phys. Chem. Solids 1963, 24, 51-62; c) M. Barrer, L. V. C. Rees, J. Phys. Chem. Solids 1964, 25, $1035-$ 1038; d) S. C. Duffy, L. V. C. Rees, J. Chromatogr. 1974, 102, 149-153; e) S. Chaudhury, A. Bhattacharya, C. Agarwal, A. Goswami, J. Phys. Chem. B 2011, 115, 9395-9400; f) K. E. Doan, B. J. Heyen, M. A. Ratner, D. F. Shriver, Chem. Mater. 1990, 2, 539-545.

[12] a) T. Okura, M. Saimaru, H. Monma, K. Yamasita, Solid State Ionics 2009, 180, 537-540; b) A. L. Despotuli, A. V. Andreeva, B. Rambabu, Ionics 2005, 11, 306-314.

[13] R. M. Izatt, J. S. Bradshaw, S. A. Nielsen, J. D. Lamb, J. J. Christensen, D. Sen, Chem. Rev. 1985, 85, 271-339. 